\title{
Mathematical modeling in economics for company logistics costs management in the context of additive technologies application
}

\author{
Gviliya Natalia Alekseevna \\ Saint Petersburg state University of \\ economics \\ Saint Petersburg, the Russian Federation \\ E-mail: natagvi@mail.ru
}

\author{
Tsenina Tatyana Tikhonovna \\ Saint Petersburg state University of \\ economics \\ Saint Petersburg, the Russian Federation \\ E-mail: cakie@yandex.ru
}

\author{
Guo Honli \\ Saint Petersburg state University of \\ economics \\ Saint Petersburg, the Russian Federation \\ E-mail: guohongli@yandex.ru
}

\begin{abstract}
Purpose of this study is advancing of scientificmethodological and applicative tools which are designed to enable management of logistics costs borne by enterprise-participant of Russia-China goods exchange and which is integrating additive technologies. The authors made up the economic-mathematic model which is demonstrating the impact of particular factors causing structural change of China's costs - logistic, currencyrelated and investment. Modeling was performed with the use of multiple regression analysis method based on 2008-2017 data package. "Quandl" aggregator was used in capacity of data source. The authors brought to light priorities in the sphere of logistics costs management exercised by the company fulfilling additive technologies integration; it was demonstrated that production-logistics costs as well as costs associated with information-related processes and supply chains management are to a greater extent exposed to transformation under the impact of additive technologies integration. The authors have examined and made up two possible forms of conventional supply chain structural transformation caused by the impact of additive technologies: supply chains "3D shop" and "Home print" both of which were developed with active use of digital technologies. The authors have also developed (i) a matrix of logistics costs of an enterprise which is integrating additive technologies and maintaining single-part and small-batch production as well and (ii) a model enabling the user to calculate logistics costs of an enterprise which is integrating additive technologies and maintaining single-part and small-batch production at preproduction phase. Use of proprietary technology enables the enterprise to forecast ( 1 month in advance) the percent of unsecured logistic costs and compensate them at the expense of currently fulfilled orders and thus allows to considerably improving efficiency of logistics costs calculation for the enterprise which is integrating additive technologies, and, therefore, ramp up efficiency of management thereof.
\end{abstract}

Key words - logistics costs, additive technologies, productionlogistic costs, costs associated with information processes and supply chain management, mathematical modeling in economics, Chinese enterprises, digital transformation of supply chains.

\section{INTRODUCTION}

China is currently one of main trade partners of Russia which fact is stipulated both by geographical and economical reasons. For today, China established partnership relations with more than 100 countries and thousands of organizations around the world, however, comprehensive strategic liaison had been established with Russia only. China and Russia are holding allencompassing mechanisms of cooperation at all levels - heads of states, governments, parliaments, armies, ruling parties, local authorities and public organizations. In particular, a representative office of the Central Bank of Russia was opened in China, and a clearing center for operations in RMB began operating in Moscow. China and Russia maintain close contacts through a number of important multilateral mechanisms, like APEC, BRICS and SCO.

However, during transition to sixth wave of innovation the process of trade intercourse undergoes considerable transformations. Firstly, this transition involves advancing of ecommerce and industrial integration of modern production technologies, namely, additive technologies. Such process leads to transformation of existing international chains of supply which results in [1]:

- Increasing imbalance of Russian-Chinese trade operations. Non-raw material resources groups of goods occupy an increasing share in the structure of Russian imports.

- Strengthening the impact of imperfect logistics infrastructure on the financial results of trade participants. Imperfection logistics infrastructure first of all means deficiency of distribution centers intended for goods delivered from China, limited number of accessible routes for cross border trading and excessive complexity of the process of customs clearance.

Aforesaid tendencies exert multiplicative effect on the cost pool of any enterprise maintaining international goods exchange between China and Russia which is integrating additive technologies into production process. Most sensitive to this effect are logistics costs. Moreover, not only absolute value thereof is increased but also proportion of logistics costs in product cost structure as well as volatility [2].

Factors like (i) absence of sufficient volume of empiric material, (ii) imperfection of global production infrastructure and additive equipment servicing and (iii) lack of qualified personnel considerably increase risk of discrepancies between anticipated logistics costs and their actual values [3, 4, 5]. At the same time, transformation of global supply chains under the impact of technological progress becomes objective reality which results in considerable improvement of automation and 
customization level of entire production, logistics and communication processes $[6,7]$. The modernization of the production processes of the enterprise participating in international trade through the integration of additive technologies will allow it to form a long-term basis for competitiveness. However, this process cannot be fulfilled without transformation of approaches to management of costs of which logistics costs are most important.

In order to prove the thesis that additive technologies are changing the global structure of logistics costs borne by Chinese enterprises maintaining foreign trade cooperation with Russia the authors have developed economic-mathematic model which is substantiating the role of logistics as a whole and particular logistics factors in the structure of foreign trade turnover of both countries [8]. The economic and mathematical model was formed on the basis of an array of data for 20082017; the source was the statistical aggregator Quandl. The foreign trade turnover of the two countries (billion \$) (Y) acted as an endogenous factor. The following factors took on the role of exogenous variables:

1. Russia's logistics efficiency index (LPI): competence and quality of customs clearance (X1);

2. Russia's logistics efficiency index (LPI): customs operations efficiency (X2);

3. Yearly average exchange rate ruble to dollar, rub. (X3);

4. Exchange rate Yuan to ruble, rub. (X4);

5. Chinese direct investments in Russia, bln. \$ (X5);

6. Russia's logistics efficiency index (LPI): supplies tracking (X6);

7. Russia's logistics efficiency index (LPI): supplies promptitude (X7);

8. Russia's logistics efficiency index (LPI): quality of infrastructure (trade, transport) (X8);

9. Russia-China Internet trade volume (import to Russia) (X9).

Sequential building of multiple regression model allowed to sequentially deny insignificant regressors and to build up an efficient model (1):

$$
\begin{gathered}
Y=-396.77+144.5 * X_{1}+69.83 * X_{2}-3.8 \\
* X_{3}+1.58 * X_{4}
\end{gathered}
$$

Adjusted coefficient of this model determination - 0.85 displays strong link between $\mathrm{Y}$ and regressors under study. The model obtained enables the authors to univocally assert that innovation and investment factors exert slight impact on foreign trade between countries. In our case, determinative are currency and logistics factors. At that, impact of logistics factors is represented by the quality of customs authorities' performance. Fig. 1 shows conceptual diagram of such impact.

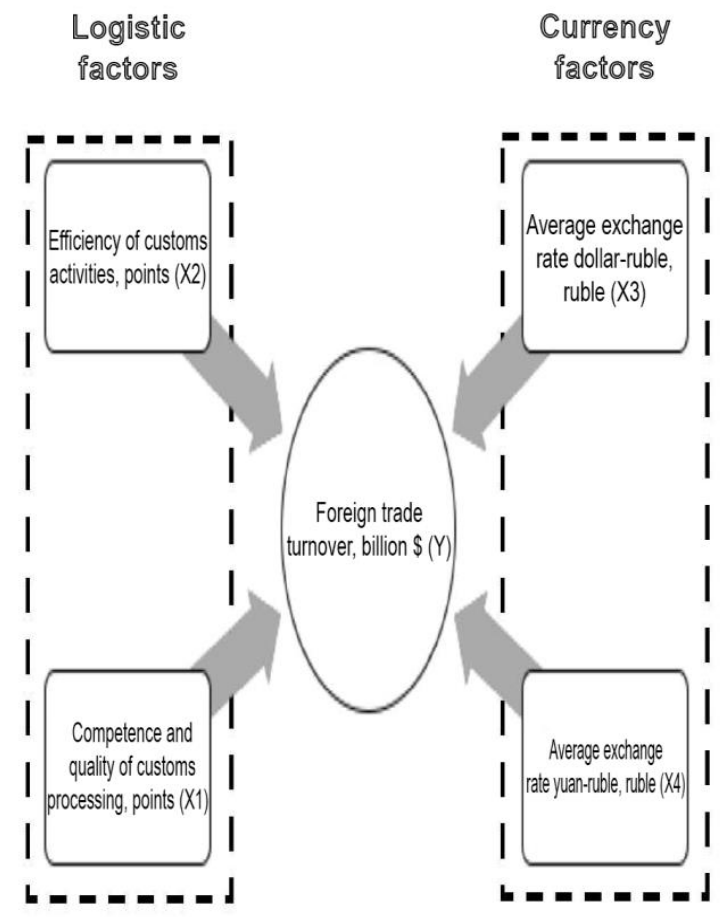

Fig. 1. A conceptual model of the impact of environmental factors on the foreign trade of Russia and China.

Equations specified herein may be consolidated into a unified regression model (2):

$$
\left\{\begin{array}{l}
Y=-396,77+144,5 * X_{1_{n}}+69,83 * X_{2_{n}}-3,8 * X_{3_{n}}+1,58 * X_{4_{n}} \\
X_{1_{n}}=0,36-0,999 \times X_{1_{n-1}}-0,959 \times C C_{X_{1_{n-1}}} \\
X_{2_{n}}=0,21-0,971 \times X_{2_{n-1}}-0,952 \times X_{2_{n-2}}-0,380 \times X_{2_{n-3}}-0,997 \times C C_{X_{2_{i}}} \\
X_{3_{n}}=4,149+0,824 \times X_{3_{n-1}}-0,733 \times X_{3_{n-2}}-0,99 \times C C_{X_{3 n-1}} \\
X_{4_{n}}=6,702+0,032 \times X_{4_{n-1}}-0,813 \times X_{4_{n-2}}-0,998 \times C C_{X_{3 n-1}}
\end{array}\right.
$$

As regards the role of logistic factors, affecting the forecast of Russia-China foreign trade exchange, namely, the proven requirement to improve customs services performance, it is worth noting that quality of customs clearance strongly depends upon state-supported financial solvency. Moreover, competence may be improved by employment of customs officers who know the Chinese language. Besides, it is essential to optimize communication with foreign economic activities participants, improve custom processing, upgrade qualification of customs officers and work out a mechanism for systematic internal quality control of customs services. To improve the efficiency of customs services provision, it is necessary to reduce the labor costs of officials and the costs of their provision. $[9,10]$

In addition to the considered logistics and currency factors, the dynamics of foreign trade is influenced by the change in the 
structure of trade turnover. Integration of additive technologies into trade activities maintained by Chinese enterprises with Russia is one of most important trends of such variations. Such trend can change the role of logistics in this process, in particular, through variation of percent and structure of logistics in the product cost.

Problem of economic efficiency of additive technologies employment is a comparatively new issue.

To a greater extent, it is considered in foreign scientific literature in the last 4 years. Weller et al. [11] studied additive production from economic viewpoint and identified effect exerted by additive production on the market structure. Authors take up the position that additive production is currently presented as a source of new industrial revolution which gives opportunities to fabricate unique items without using special tooling which in fact, in case of monopoly, allows increasing enterprise incomes due to the use of consumers' surplus through establishment of flexible production-logistics system supposing individual orders implementation. Gress \& Kalafsky [12] submit that additive technologies may change geography of production in general and thus affect structure of demand and consumption as well as innovations and global supply chains. More globally the problem of prospects of logistics transformation and supply chains change in the course of additive production integration is disclosed in Cozmei \& Caloian [13] where (i) decreasing of standing expenses, (ii) omission of costs associated with additional equipment purchasing and amortization costs connected therewith and (iii) decrease of risks and management costs reduction are being considered as economic advantages of additive technologies in logistics application environment; Mellor et al [14] point out that until recent time additive technologies were used only in the area of prototyping, however, in the current context it became possible to build up full-fledged production based on additive technologies because the latter (i) provide practically unlimited opportunities in the sphere of end product design, (ii) do not require special tooling and (iii) ensure low productionlogistics costs. Most profound research in the area of additive production was done by Gebler et al. $[15,16]$ who submit that most intensified development of additive technologies in the nearest future will take place in small-batch production, unique items production and in the sphere of expensive equipment manufacturing. Besides, the authors were first to examine variation of structure of production-logistics costs in the condition of 3D-printing application.

Based on findings upon literature analysis, the authors of this paper enunciate the following main targets of the current study:

- develop an economic-mathematic model demonstrating that logistic, investment and currency factors are governing the change of Chinese logistics costs structure;

- define priorities in logistics costs management of such enterprise;

- consider applied aspects of logistics costs transformation at Chinese enterprises which are integrating additive technologies;
- build up the model of predictive calculation of logistics costs and predictive compensation of unsecured logistics costs of Chinese enterprise integrating additive technologies.

\section{MATERIALS AND METHODS}

International Russia-China cooperation is characterized by specific logistics costs. The authors built up an economicmathematic model proving that there are particular factors causing Chinese logistics costs structure variation. Modeling was performed based on 2008-2017 data array; the source was the statistical aggregator Quandl. Annual integrated index of Chinese logistics costs (Z), billion \$ was used as an endogenous variable; variables $\mathrm{X} 1$ - X9 from model (1) were used in capacity of exogenous variables. Selection of the above factors had systematic nature. The totality of indices shown may be investigated with the use of multiple regression tools. Creation of multiple regression model allowed to sequentially deny insignificant regressors and to build up the following efficient model (3):

$$
\begin{aligned}
Z=-18501.42 & +9899.3 \times X_{1_{n}}-163.06 \\
& \times X_{3_{n}}+106.77 \times X_{4_{n}} \\
& +429.92 \times X_{5_{n}}
\end{aligned}
$$

Adjusted coefficient of this model determination - 0.96 displays strong link between $\mathrm{Z}$ and regressors under study. Therefore, we have developed the multiple regression model according to which dynamics of Chinese logistics costs depends upon three types of factors: logistics, currency and investments. Fig. 2 shows conceptual diagram of such impact.

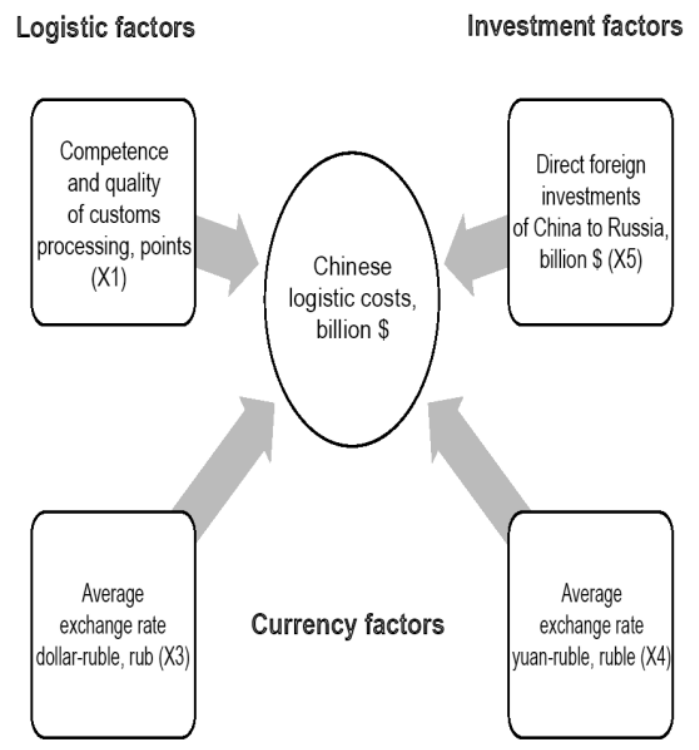

Fig. 2. Conceptual diagram of external environment factors impact exerted on China's logistics costs

In order to estimate future values of respective model regressors it was decided to use ARIMA-class models. Equations specified herein may be consolidated into a unified regression model (4): 


$$
\left\{\begin{array}{l}
Z=-18501,42+9899,3 \times X_{1_{n}}-163,06 \times X_{3_{n}}+106,77 \times X_{4_{n}}+429,92 \times X_{5_{n}} \\
X_{1_{n}}=0,36-0,999 \times X_{1_{n-1}}-0,959 \times C C_{X_{1 n-1}} \\
X_{3_{n}}=4,149+0,824 \times X_{3_{n-1}}-0,733 \times X_{3_{n-2}}-0,99 \times C C_{X_{3 n-1}} \\
X_{4_{n}}=6,702+0,032 \times X_{4_{n-1}}-0,813 \times X_{4_{n-2}}-0,998 \times C C_{X_{3 n-1}} \\
X_{5_{n}}=0,552-0,765 \times X_{1_{n-1}}-0,655 \times X_{1_{n-2}}-0,703 \times X_{1_{n-3}}
\end{array}\right.
$$
)

Obtained system of equations allows to vividly estimating the level of China's logistics costs. Incremental increase of this index is worth mentioning. To a great extent this is associated with considerable growth of foreign trade turnover represented by machines and equipment, in particular. Therefore, transition to advanced production technologies will inevitably increment this index, first of all, in terms of its volatility growth. In particular, additive technologies integration into production processes of industrial enterprises may change (i) structure of industrial products consumption, (ii) structure of logistics costs arising in the course of production process and (iii) structure of global supply chains.

\section{RESULTS}

Thus, it is possible to state that conventional industrial production will undergo transformation under the impact of additive technologies advancement and this will inevitably cause substantive and structural changes of global supply chains. It is possible to identify two forms of structural transformation of conventional supply chains: supply chain: "3D shop" and supply chain "Home print" (Fig. $3 \& 4$ ) both of which are based on active employment of digital technologies.

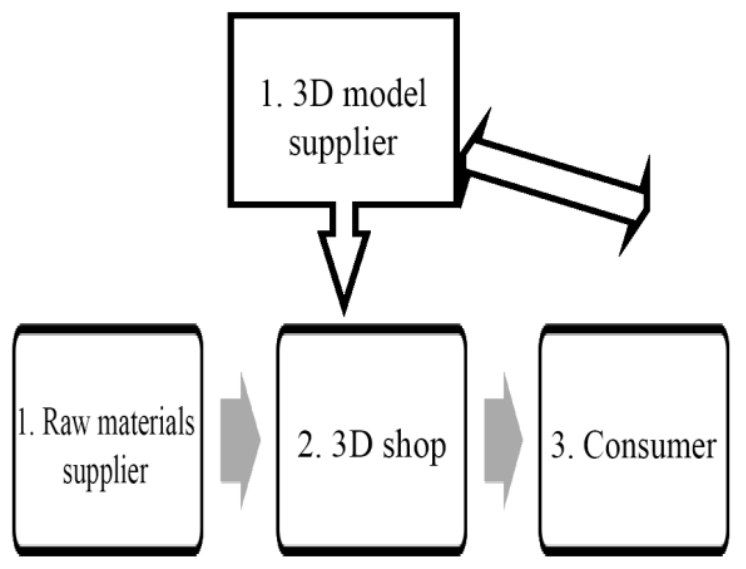

Fig. 3. Supply chain "3D shop"

Within this supply chain model it is planned to completely exclude large industrial enterprises. This model is first of all characterized by universalism and scalability. However, system of interaction between 3D shop and consumer in terms of finished goods transportation does not differ from a conventional one.

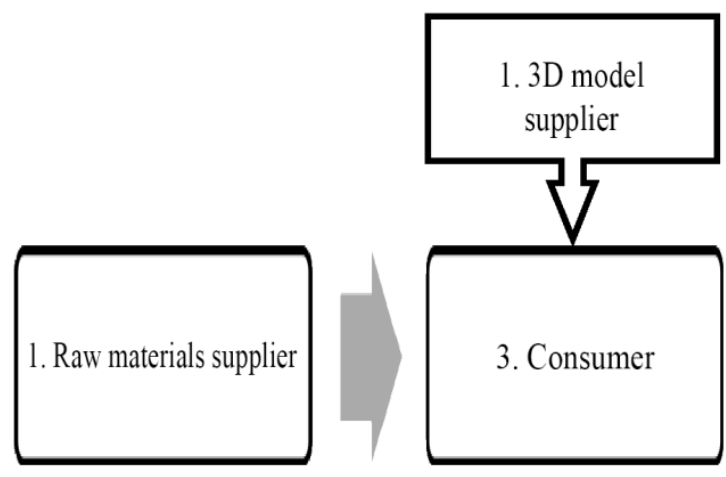

Fig. 4. Supply chain "Home print"

Within this supply chain model it is proposed to completely exclude the manufacturer. Advancement of the said supply chain assumes considerable reduction of industrial sector with simultaneous development of digital logistics services. Necessity to organize raw and other materials supplies for printing by small inconstant batches will inevitably lead to emerging of individual market of logistics middlemen who are capable to work directly with B2C market consumers.

Therefore, transformation of supply chains in the condition of additive technologies integration into production process will be permanent and this will affect, in turn, all the elements of enterprise costs. However, additive technologies, even in the condition of classic supply chains, assume large-scale transformation of technological processes in terms of their resource-related constituent which is also leading not only to enterprise costs change but also to the necessity to set-up essentially new tools of calculation and forecasting thereof.

It is possible to identify the following main groups of logistics costs falling under transformation in condition of additive technologies integration. [1] These groups are significantly differentiated in accordance with the radical nature of these transformations. First of all let us consider transportation costs. This type of logistics costs is least of all prone to transformation under the impact of additive technologies integration. Stock management costs are being structurally transformed in terms of calculation and forecasting that is first of all demanding to take into consideration the recycling effect. Then, let us consider customs costs. This group is to the less extent prone to transformation caused by additive technologies integration in production. As regards costs associated with information processes and supply chains management, this kind of logistics costs to a great extent depends upon the structure of production process. Therefore, they must be considered in combination with productionlogistics costs. Namely these costs are to larger extent prone to transformation caused by additive technologies integration. Thus, it is possible to identify priorities in logistics costs management for the enterprise which is integrating additive 
technologies. It is expedient to shape such prioritization in the form of pyramid where the higher level will be represented by logistics costs of top-priority management since they constitute the largest percent in total logistics costs and, as we are moving down the pyramid, it is expected that order of priority in logistics costs management will be falling (refer to Fig. 5).

5. Production-logistics costs

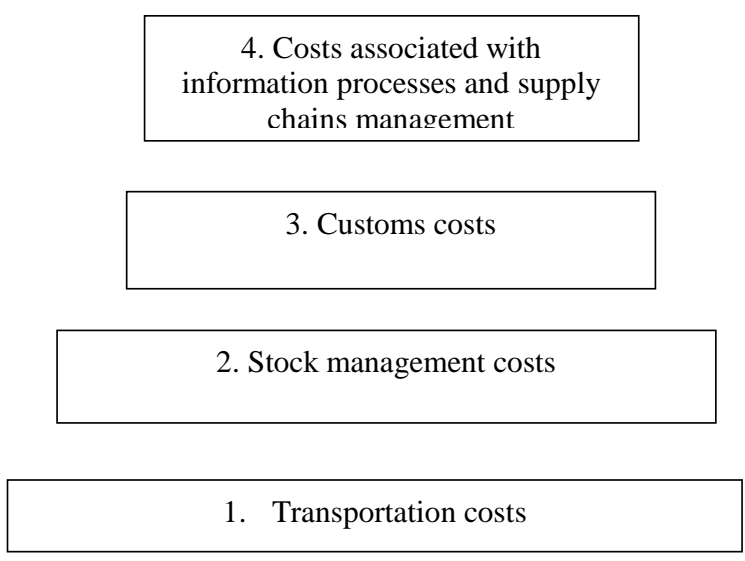

Fig. 5. Priorities in logistics costs management for enterprise which is integrating additive technologies

It is possible to identify the following totality of tools which are necessary for the purpose of logistics costs management at this enterprise:

1. Model of logistics costs calculating at pre-production phase. This model will be intended to correctly determine the value of earlier considered elements of logistics costs for the purpose of price formation.

2. Demand estimation model. This model is a constituent component of logistics costs calculating at pre-production phase. Enterprise using this model is capable to estimate potential demand and thus establish additional stock of raw and other materials.

This case assumes binary mixed classification according to which we can identify 2 classification features. Primary classification feature is represented by the group of enterprise resources being utilized [5]. In this case, logistics costs may be divided into the following groups:

1. Depreciation of logistics equipment and servicing of transportation facilities;

2. Logistics personnel labor payment expenditures;

3. Expenditures for raw and other materials to support logistics processes;

4. Other logistics cost

Secondary feature in this case is represented by logistics costs classification earlier presented by Fig. 5:

1. Transportation costs;

2. Stock management costs;
3. Customs costs;

4. Costs associated with information processes and supply chains management;

5. Production-logistics costs

Therefore, the totality of calculation elements may be represented in the form of respective matrix 3 by 4 . The authors are identifying this matrix as matrix of logistics costs of an enterprise which is integrating additive technologies and maintaining single-part and small-batch production (refer to Table 1).

TABLE 1. MATRIX OF LOGISTICS COSTS OF AN ENTERPRISE WHICH IS INTEGRATING ADDITIVE TECHNOLOGIES AND MAINTAINING SINGLE-PART AND

\begin{tabular}{|c|c|c|c|c|c|}
\hline & 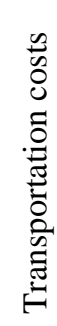 & 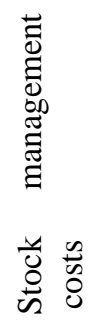 & 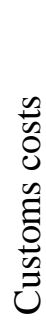 & 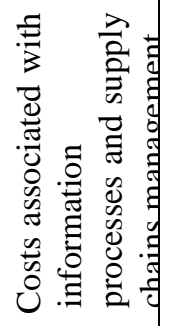 & 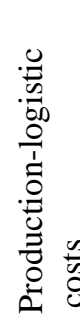 \\
\hline $\begin{array}{l}\text { Depreciation of } \\
\text { logistics } \\
\text { equipment and } \\
\text { servicing of } \\
\text { transportation } \\
\text { facilities }\end{array}$ & $\mathrm{A}_{1}$ & $\mathrm{~A}_{2}$ & - & - & $\mathrm{A}_{5}$ \\
\hline $\begin{array}{l}\text { Logistics } \\
\text { personnel labor } \\
\text { payment } \\
\text { expenditures }\end{array}$ & $\mathrm{P}_{1}$ & $\mathrm{P}_{2}$ & $\mathrm{P}_{3}$ & $\mathrm{P}_{4}$ & $\mathrm{P}_{5}$ \\
\hline $\begin{array}{l}\text { Expenditures } \\
\text { for raw and } \\
\text { other materials } \\
\text { to support } \\
\text { logistic } \\
\text { processes }\end{array}$ & $\mathrm{M}_{1}$ & $\mathrm{M}_{2}$ & - & - & $\mathrm{M}_{5}$ \\
\hline $\begin{array}{l}\text { Other logistic } \\
\text { costs }\end{array}$ & - & - & $\mathrm{O}$ & - & - \\
\hline
\end{tabular}

Let us first of all consider depreciation of logistics equipment and costs associated with transport facilities servicing with reference to transportation costs $\left(A_{1}\right)$. These elements may be valuated in compliance with annual, monthly or quarterly norms. It is necessary to introduce a coefficient reflecting the share of the relevant order in the annual volume of shipments $\left(\mathrm{r}_{\mathrm{A} 1}\right)$. Distance to be covered by vehicle stock and vessels and time consumed shall be the basis for this coefficient 
calculation. It is necessary to take into consideration the fact that process of transportation may refer to more than one order simultaneously. Therefore, it is also necessary to introduce a coefficient reflecting the share of the relevant order in the totality of simultaneously transported orders $\left(\mathrm{s}^{\mathrm{n}}\right)$.

Let us further consider depreciation of logistics equipment and costs associated with transport facilities servicing with reference to stock management costs $\left(\mathrm{A}_{2}\right)$. In this case, the basis for calculation is difficult to identify. Process of these costs calculation within Order $\mathrm{n}$ may be universalized by means of the following coefficients: $r_{a 2} .^{n}-$ proportional coefficient referring to depreciation of warehousing equipment used for Order $\mathrm{n}$ fulfillment; $\mathrm{r}_{\mathrm{a} .2^{\mathrm{n}}}{ }^{\mathrm{n}}$ - proportional coefficient referring to cost of scheduled repair and servicing of warehousing equipment used for Order $n$ fulfillment.

Costs associated with transportation of return materials and finished goods are made account of only within productionlogistics costs. Since the calculation base in this case is time, the following refinement coefficients can be formed: $r_{a 5.1}{ }^{n}-$ proportional coefficient of depreciation and cost of scheduled servicing of equipment employed in the process of intraproductive handling of objects relating to unfinished Order $\mathrm{n} ; \mathrm{r}_{\mathrm{a} 5.2^{\mathrm{n}}}$ - proportional coefficient of depreciation and cost of scheduled servicing of equipment employed in the process of intraproductive handling of finished product relating to Order $\mathrm{n}$; and $\mathrm{r}_{\mathrm{a} .3^{\mathrm{n}}}{ }^{\mathrm{n}}$ - proportional coefficient of depreciation and cost of scheduled servicing of equipment employed in the process of intraproductive handling of recycling objects relating to Order $\mathrm{n}$. Thus, the sum of respective costs elements enables us to determine the planned value of logistics equipment depreciation and transport facilities servicing for Order calculation. Risks of logistics equipment failure should be also mentioned. Poisson formula may be used to evaluate the possibility of emerging of the group of risks under this study.

Further, it is necessary to analyze most large-scale groups of logistics costs - logistics personnel labor expenditures and costs associated with raw and other materials to support logistics processes. Distance required for particular order fulfillment may be the basis for calculation in this case.

Sub-models presented may be aggregated into a unified model of mixed-type (5). Presented model makes it possible to calculate logistics costs of enterprise which is integrating additive technologies and maintaining single-part and smallbatch production at pre-production phase of order implementation. Most part of this model's constituents are monomeric from the view point of their definition and may be calculated from statistical data, expertly or established discretely.

$$
\begin{aligned}
& \log _{n}=s^{n} \times\left(\frac{D_{x}^{n}}{D_{x}^{t}} \times a_{1.1}^{t}+\frac{D_{z}^{n}}{D_{z}^{t}} \times a_{1.2}^{t}+\frac{T_{x}^{n}}{T_{x}^{t}}\right. \\
& \left.\times a_{1.3}^{t}+\frac{T_{x}^{n}}{T_{z}^{t}} \times a_{1.4}^{t}\right)+\frac{W_{y}^{n}}{W_{y}^{t}} \\
& \times a_{2.1}^{t}+\frac{T_{y}^{n}}{T_{y}^{t}} \times a_{2.2}^{t}+\frac{T_{f}^{n}}{T_{f}^{t}} \\
& \times\left(a_{5.1}^{t}+a_{5.2}^{t}\right)+\frac{T_{c}^{n}}{T_{c}^{t}} \\
& \times\left(a_{5.3}^{t}+a_{5.4}^{t}\right)+\frac{2,97 \times T_{l}^{n}}{T_{l}^{t}} \\
& \times\left(a_{5.5}^{t}+a_{5.6}^{t}\right) \\
& +\left(1-e^{-\frac{N_{x}^{m}}{N_{x}^{m a x}}}\right) \times C_{x}^{m} \times \frac{T_{x}^{n}}{T_{x}^{t}} \\
& +\left(1-e^{-\frac{N_{z}^{m}}{N_{z}^{m a x}}}\right) \times C_{z}^{m} \times \frac{T_{x}^{n}}{T_{z}^{t}} \\
& +\left(1-e^{-\frac{N_{y}^{m}}{N_{y}^{\max }}}\right) \times C_{y}^{m} \times \frac{T_{y}^{n}}{T_{y}^{t}} \\
& +\left(1-e^{-\frac{N_{f}^{m}}{N_{f}^{m a x}}}\right) \times C_{f}^{m} \times \frac{T_{f}^{n}}{T_{f}^{t}} \\
& +\left(1-e^{-\frac{N_{c}^{m}}{N_{c}^{\max }}}\right) \times C_{c}^{m} \times \frac{T_{c}^{n}}{T_{c}^{t}} \\
& +\left(1-e^{-\frac{N_{l}^{m}}{N_{l}^{m a x}}}\right) \times C_{l}^{m} \\
& \times \frac{2,97 \times T_{l}^{n}}{T_{l}^{t}}+Q \\
& \times\left(\frac{T_{d}^{n}}{60} \times P_{d}^{h} \times N_{d}^{n}\right. \\
& +\sum_{i}^{m} \frac{T_{s t_{i-m}}^{n}}{60} \times P_{s t_{i-m}}^{h}+\frac{T_{c u s}^{n}}{60} \\
& \times P_{c u s}^{h}+\frac{T_{v e n}^{n}}{60} \times P_{v e n}^{h} \\
& \left.+\sum_{i}^{m} \frac{T_{p r \cdot \log _{i-m}}^{n}}{60} \times P_{p r . \log _{i-m}}^{h}\right) \\
& +\frac{D_{x}^{n} \times E x p_{x}^{n}}{100} \times P r_{x} \\
& +\frac{D_{y}^{n} \times E x p_{y}^{n}}{100} \times P r_{e l}+P r_{e l} \\
& \times\left(\frac{D_{f}^{n} \times E x p_{f}^{n}}{100}+\frac{D_{c}^{n} \times E x p_{c}^{n}}{100}\right. \\
& \left.+\frac{2,97 \times D_{l}^{n} \times \operatorname{Exp}_{l}^{n}}{100}\right)+O_{n}
\end{aligned}
$$




\section{DISCUSSION}

Earlier established logistics facilities load coefficient (Q) is intended to reflect level of providing the enterprise logistics facilities with required Order's scope and labor input. This is stipulated by the fact that already set-up model of calculation incorporates complex elements where time is the basis for calculation thereof. Obviously, no enterprise can avoid downtime in its activities. Logistics personnel as well as logistics equipment cannot be employed continuously. Partial load results in unsecured costs which are increasing the product cost with sales deduction caused by decrease in demand on the background of which these costs are emerging. Presented coefficient $\mathrm{Q}$ allows accounting these unsecured logistics costs and increase, in proportion to their growth, the final value of aggregate logistics costs.

Deterministic approach cannot be used to forecast this coefficient because their dynamics may be affected by indirect factors. It is possible to identify the following factors affecting the degree of logistics facilities loading:

1. Quantity of orders $\left(\mathrm{X}_{1}\right)$

2. Average value of one order $\left(X_{2}\right)$;

3. Timing factor (quarter order number) $\left(\mathrm{X}_{3}\right)$.

Endogenous factor may be represented by proportion of unsecured logistics costs $(\mathrm{Y})$ which is calculated by the following formula (6):

Where:

$$
Y_{i}=\frac{U n \cdot \log _{i}}{\log _{i}}
$$

1. $\quad \log _{\mathrm{i}}-\operatorname{logistics}$ costs borne for time period $\mathrm{i}$;

2. Un. $\log _{\mathrm{i}}$ - unsecured logistics costs borne for time period i (logistics losses).

Primary inputs for analysis were presented by a small Chinese enterprise maintaining single-part and small-batch production. Further regression analysis resulted in below equation (7):

$$
\begin{gathered}
Y_{i}=0.38-0.0035 \times X_{1_{i}}+(7.777 E-0.8) \\
\times X_{2_{i}}
\end{gathered}
$$

Further regression analysis resulted in below equation (6):

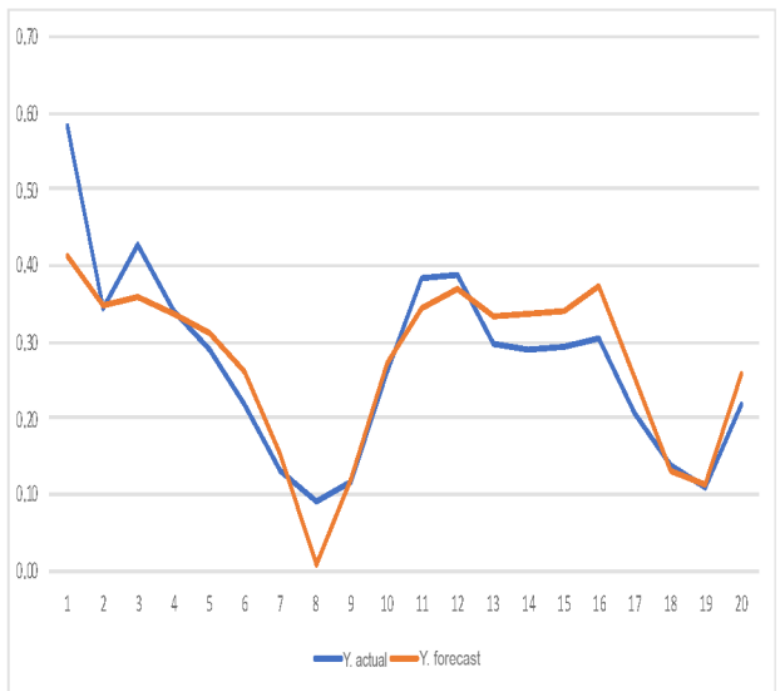

Figure 6. Dynamics of physical and theoretical values of Y (percent of unsecured logistic costs).

In order to estimate $\mathrm{Y}$ value it is required to set up the system of predictive models intended to forecast exogenous variables. In this case, most efficient results were demonstrated by ARIMA models $(1,0,1)$ :

$$
X_{1_{i}}=20.99-0.59 \times X_{1_{i-1}}-0.95 \times M A_{X_{1_{i-1}}}
$$

$$
X_{2_{i}}=2149347+0.415 \times X_{2_{i-1}}-0.71 \times M A_{X_{2_{i-1}}}
$$

$\mathrm{Q}$ value, in its turn, is linearly dependent upon the value of unsecured logistics costs. Basic value of $\mathrm{Q}$ is 1 , while incrementing of $\mathrm{Y}$ is proportionally incrementing $\mathrm{Q}$. Corresponding coefficient is set up for each month on the basis of demand frequency and average order value of the preceding month. Presented models may be consolidated in (8):

$Q_{i}=1.38-0.0035$

$$
\begin{aligned}
& \times\left(20.99-0.59 \times X_{1_{i-2}}\right. \\
& \left.-0.95 \times M A_{X_{1_{i-2}}}\right) \\
& +(7.777 E-0.8) \\
& \times(2149347+0.415 \\
& \left.\times X_{2_{i-2}}-0.71 \times M A_{X_{2_{i-2}}}\right)
\end{aligned}
$$

Corresponding estimated values enable the enterprise to forecast (1 month in advance) percent of unsecured logistics costs and to compensate them at the expense of currently fulfilled orders. Thus, model of logistics personnel labor expenditures calculation for Order $\mathrm{n}$ in month I shall be as follows (9): 


$$
\begin{aligned}
P_{n_{i}} & =(1.38-0.0035 \\
& \times\left(20.99-0.59 \times X_{1_{i-2}}\right. \\
& \left.-0.95 \times M A_{X_{1_{i-2}}}\right) \\
& +(7.777 E-0.8) \\
& \times(2149347+0.415 \\
& \left.\left.\times X_{2_{i-2}}-0.71 \times M A_{X_{2_{i-2}}}\right)\right) \\
& \times\left(\frac{T_{d}^{n}}{60} \times P_{d}^{h} \times N_{d}^{n}\right. \\
& +\sum_{i}^{m} \frac{T_{\text {st }}^{n}}{60} \times P_{\text {st }}^{h}+\frac{T_{\text {cus }}^{n}}{60} \\
& \times P_{\text {cus }}^{h}+\frac{T_{\text {ven }}^{n}}{60} \times P_{\text {ven }}^{h} \\
& \left.+\sum_{i}^{m} \frac{T_{\text {pr.log }}^{n}}{60} \times P_{\text {pr. } \log _{i-m}}^{h}\right)
\end{aligned}
$$

The presented model makes it possible to considerably improve efficiency of calculation of logistics costs borne by an enterprise integrating additive technologies and, therefore, improve efficiency of management thereof.

\section{CONCLUSION}

Authors of this paper (i) studied the features of logistics costs of an enterprise which is integrating additive technologies, (ii) examined the current structure of logistics costs of enterprise- participant of Russia-China goods exchange , (iii) performed analysis of impact exerted by emerging market of additive technologies on the structure of global supply chains which results in the necessity to increase digital technologies employment, (iv) examined applied aspects of logistics costs transformation at Chinese enterprises which are integrating additive technologies, (v) developed a model of predictive calculation of logistic costs and predictive compensation of unsecured logistics costs of Chinese enterprise which is integrating additive technologies in single-part and small-batch production.

\section{REFERENCES}

[1] Scherbakov V., Smirnova E. GLOBAL SUPPLY CHAIN IMPERATIVES. Journal of Applied Economic Sciences. 2018. T. 13. № 7 (61). C. 1888-1901.

[2] Konnikov E.A., Pogrebova O.A., MaskovaYu.R., Glukhov V.V. Real options valuation of additive production // В сборнике: Reliability, Infocom Technologies and Optimization (Trends and Future Directions) 6th International

Conference ICRITO. 2017. C. 557-563.

[3] Gviliya N.A., Tsenina Ye.V. Formation of KPI system for procurement management of corporation and its suppliers. // Problems of modern economics. Eurasian international scientific-analytical magazine. 2017. No. 1 (61). p.97-100.

[4] Gizatullina O.M., Grankina S.V. Logistic costs of Russian enterprises.// Messenger of Samara State Transport University. 2018. No.1(39). p. 3040.
[5] Maydanova, S., Ilin, I. Problems of the preliminary customs informing system and the introduction of the Single Window at the sea check points of the Russian Federation (2018) 239, 04004.

[6] Kuznetsova T.V. Logistic costs: economic content, composition, typology. // Economics and management. 2012. No.3. p.29-34.

[7] Gviliya N. A., Rundygina D. D. Management of logistic costs in the chain of book products supply. // Business. Education. Justice. 2019. No. 1 (46). p. 136-143.

[8] Guo Honli Model of accounting the logistic factors within Russia-China goods exchange development.// Economics and justice issues. 2018. No.12 (126). p. 91-95

[9] Tsenina T.T. Changes in Russia-China international trade. // In collection book: Logistics and supply chains management. Collection of scientific articles. Saint Petersburg, 2017. p. 90-92.

[10] Tsenina Ye.V. Risks in production logistics (reference to companies operating in Russian market). // Journal of South-West state University. 2014. No.2 (53). p. 85-91.

[11] Weller, C.; Kleer, R.; Piller, F.T. Economic implications of 3D printing: Market structure models in light of additive manufacturing revisited. International Journal of Production Economics 2015, 164, 43-56, doi:10.1016/j.ijpe.2015.02.020.

[12] Gress, D.R.; Kalafsky R.V. Geographies of production in 3D: Theoretical and research implications stemming from additive manufacturing. Geoforum 2015, 60, 43-52, doi:10.1016/j.geoforum.2015.01.003.

[13] Cozmei, C., Caloian, F. Additive manufacturing flickering at the beginning of existence. Procedia Economics and Finance 2012, 3, 457462, doi: 10.1016/S2212-5671(12)00180-3

[14] Mellor, S.; Hao, L.; Zhang D. Additive manufacturing: A framework for implementation. International Journal of Production Economics 2014, 149, 194-201, doi:10.1016/j.ijpe.2013.07.008.

[15] Gebler, M.; SchootUiterkamp, A.J.M.; Visser C. A global sustainability perspective on 3D printing technologies. Energy Policy 2014, 74 (C), 158-167, doi:10.1016/j.enpol.2014.08.033.

[16] Schniederjans, D.G. Adoption of 3D-printing technologies in manufacturing: A survey analysis. International Journal of Production Economics 2017, 183, 287-298; doi:10.1016/j.ijpe.2016.11.008. 